\title{
A mask for rabbit stereotaxic gas anesthesia
}

\author{
MICHAEL M. PATTERSON \\ Ohio University, Athens, Ohio 45701 \\ and \\ I. GORMEZANO \\ University of Iowa, Iowa City, lowa 52240
}

\begin{abstract}
A mask suitable for delivering gas anesthesia to a rabbit in a stereotaxic headholder is described. The mask allows simple delivery of any volatile anesthesia to the rabbit for long periods during stereotaxic surgery, providing an ideal means for rabbit anesthesia when recovery is important.
\end{abstract}

The rabbit is a useful animal for many kinds of behavioral and neurophysiological studies (e.g., Gormezano, Schneiderman, Deaux, \& Fuentes, 1962; Cegavske, Thompson, Patterson, \& Gormezano, 1976; Berger \& Thompson, Note 1; Patterson, Note 2). While providing a behaviorally cooperative subject, the use of the animal in stereotaxic surgery is considerably more difficult than is the cat. While the cat has well placed skull features for stereotaxic mounting, the rabbit must be held with somewhat less accurate and cumbersome means (Patterson, Note 2). In addition, the cat can easily be intubated with noninjurious endotracheal tubes, allowing for delivery of gas anesthesia during stereotaxic surgery, whereas the rabbit is very difficult, if not impossible, to intubate under normal conditions. Thus, most rabbit stereotaxic surgery is performed under an injectable anesthesia, which is often not well tolerated (Patterson, Note 2), and recovery time is often substantial. The ability to utilize an easily controlled, delivered, and well tolerated gas anesthesia such as halothane or penthrane during stereotaxic surgery with the rabbit would make such surgery simpler and less risky. The mask described here was developed to allow gas delivery to the rabbit in a Kopf stereotaxic head holder and has proved to give good results over several hours of surgery followed by complete, nontraumatic recovery from anesthesia.

\section{CONSTRUCTION}

The mask itself is shown in Figure 1. It consists of three pieces of Plexiglas tubing, a Plexiglas plate, and a

The mask was developed while the authors were Visiting Associate Professor and Visiting Professor, respectively, at the Department of Psychobiology, University of California, Irvine. The support of NSF Grant BNS 76-84561 to I. Gormezano and NINCDS Grant R01-NS10647 to M. M. Patterson is gratefully acknowledged. Requests for reprints should be sent to Michael M. Patterson, College of Osteopathic Medicine, Ohio University, Athens, Ohio 45701. rubber face adapter. The large tube forms the body of the mask and is cut from a tube $50 \mathrm{~mm}$ (about 2 in.) O.D., $42 \mathrm{~mm}$ (about 1-1/4 in.) I.D., and about $50 \mathrm{~mm}$ long. This tube is cut at a 45-deg angle, starting from $3 \mathrm{~mm}$ from the front and slanting down to the back. Starting at the 3-mm point from the front, the sides are then cut down about $20 \mathrm{~mm}$ on the right (when viewed from the front) and about $12 \mathrm{~mm}$ on the left, leaving a $3-\mathrm{mm}$ rim on the top of the mask. Holes $21 \mathrm{~mm}(7 / 8 \mathrm{in}$.) in diameter and centered $15 \mathrm{~mm}$ back and $10 \mathrm{~mm}$ below the horizontal midline are drilled into the body tube. Side tubes $21 \mathrm{~mm}$ (7/8 in.) O.D., $18 \mathrm{~mm}(3 / 4 \mathrm{in}$.) I.D., and $38 \mathrm{~mm}(1-1 / 2 \mathrm{in}$.) long are sealed into the holes with Plexiglas solvent (e.g., ethylene dichloride). The side tubes slant down to allow attachment of flexible anesthesia tubes under the stereotaxic frame bars. A round 3-mm thick plate with a diameter that of the body tube is sealed to the front of the tube. The plate has a milled slot $25 \mathrm{~mm}$ long and $3 \mathrm{~mm}$ wide centered side to side with the top of the slot on the horizontal midline. The slot is just large enough to pass the Kopf tooth bar. A flexible rubber membrane is sewn to the mask through $1-\mathrm{mm}$ holes drilled around the open sides. The sewing is done using

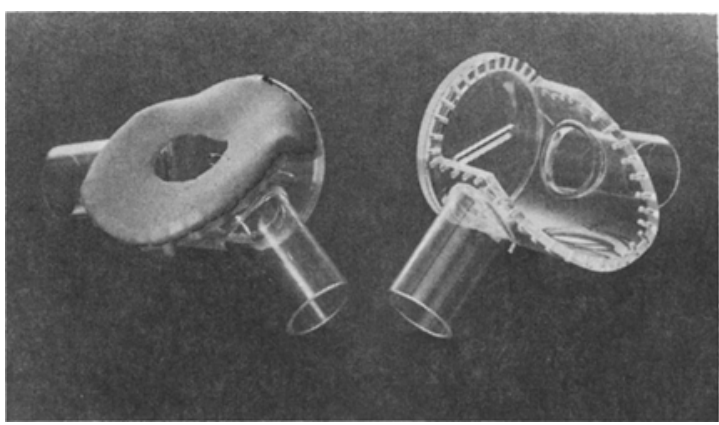

Figure 1. The rabbit anesthesia mask complete (left) and without the rubber membrane attached. Note the asymmetry of the sides in relation to the front slot, and side tubes and suturing holes visible on the incomplete model. 
a 0 or 1 silk suture swaged to a quarter curved needle. Since the rubber must be airtight around the mask, the suture is brought back through each hole twice to provide a continuous loop over the rubber. We did not find a glue that would adhere well enough to join the vinyl rubber to the Plexiglas. However, other rubbers or other glues can undoubtedly be used to make the sewing unnecessary. A hole about $12 \mathrm{~mm}$ in diameter is cut in the rubber to allow the animal's nose and mouth to enter the mask, but provide a snug fit.

\section{OPERATION}

The mask is fitted to the Kopf rabbit adapter as shown in Figure 2. The slot fits tightly over the tooth bar and the space in the bar is filled with clay to provide a seal. The asymmetric side cuts in the main tube allow the nose clamp on the right to come down to the animal's nose while providing a higher support on the left. To position the animal, the mask is pushed as far back onto the bar as possible. Initial anesthesia is given by a regular small animal face cone while the animal is in a restraining box or wrapped in a towel. If halothane is used, a $5 \%$ concentration in oxygen produces sufficient anesthesia in about $15 \mathrm{~min}$. The animal can then be placed on the tooth bar, the mask slid up over the nose and mouth and gas flow started through the mask. It is easiest to have two sets of hoses for the anesthesia machine, one attached to the cone and one to the mask, switching hoses at the machine rather than from cone to mask. Attempting to place the hoses on the mask after the animal is in place is difficult and may take longer than the time available before the animal becomes too light. It is very important when adjusting the animal in the mask to make sure the mouth is well into the chamber and open, with the tongue out. This can be accomplished by pushing a set of hemostats inside the rubber and spreading the mouth while lightly grasping the tongue. If the mouth is closed, the animal may slowly become hypoxic since, with the nose clamp in place, breathing is largely through the mouth. If the animal suddenly expires some time after being placed in the apparatus, slow suffocation leading to vomiting and aspiration is to be suspected, probably due to the mouth not being sufficiently open. Care should also be taken that a good respiration volume is maintained and that no leaks around the mask are present. Once the animal is secured in the mask and the nose clamp is down, the zygoma clamps may be adjusted into position and the gas mixture changed to maintenance levels $\left(1 \%-1 \frac{11}{2} \%\right.$ for halothane).

When used properly, the mask maintains excellent anesthesia levels for many hours. Problems are usually due to improper mask position, allowing leakage or blocking proper ventilation of the animal. Used

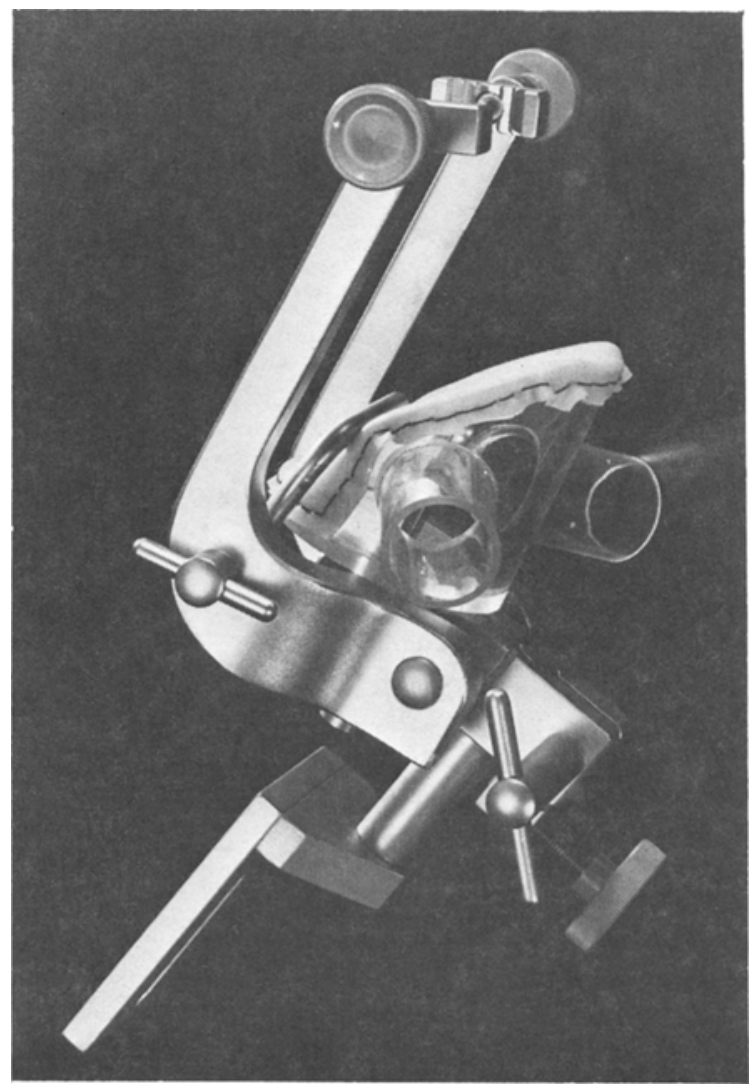

Figure 2. The mask mounted on the Kopf adapter.

properly, the mask allows rabbits to be easily maintained on gas anesthesia during stereotaxic surgery over long periods with practically no anesthesia connected fatalities.

\section{REFERENCE NOTES}

1. Berger, T. W., \& Thompson, R. F. Functional division among hippocampal cell types during classical conditioning. Paper presented at Psychonomic Society Meeting, Washington, D.C., 1977.

2. Patterson, M. M. Rabbit stereotaxic techniques. DKI Carrier, David Kopf Instruments, 7324 Elmo Street, Tujunga, California, 1977, 4 (1).

\section{REFERENCES}

Cegavski, C., Thompson, R. F., Patterson, M. M., \& Gormezano, I. Mechanisms of efferent neuronal control of the reflex nictitating membrane response in the rabbit. Journal of Comparative and Physiological Psychology, 1976, 90 (5), 411-423.

Gormezano, I., Schneiderman, N., Deaux, E. D., \& Fuentes, I. Nictitating membrane: Classical conditioning and extinction in the albino rabbit. Science, 1962, 138, 33-34. 